\title{
Mechanical, Thermal and Crystallization Properties of Polypropylene (PP) Reinforced Composites with High Density Polyethylene (HDPE) as Matrix
}

\section{Harekrushna Sutar ${ }^{1,2}$, Prakash Chandra Sahoo², Prateekshya Suman Sahu², Surajabala Sahoo², Rabiranjan Murmu' ${ }^{2}$, Sumit Swain², Subash Chandra Mishra1}

\author{
${ }^{1}$ Department of Metallurgical and Materials Engineering, National Institute of Technology, Rourkela, India \\ ${ }^{2}$ Department of Chemical Engineering, Indira Gandhi Institute of Technology, Sarang, India \\ Email: ^h.k.sutar@gmail.com
}

How to cite this paper: Sutar, H., Sahoo, P.C., Sahu, P.S., Sahoo, S., Murmu, R., Swain, S. and Mishra, S.C. (2018) Mechanical, Thermal and Crystallization Properties of Polypropylene (PP) Reinforced Composites with High Density Polyethylene (HDPE) as Matrix. Materials Sciences and Applications, 9, 502-515.

https://doi.org/10.4236/msa.2018.95035

Received: January 11, 2018

Accepted: May 21, 2018

Published: May 24, 2018

Copyright $\odot 2018$ by authors and Scientific Research Publishing Inc. This work is licensed under the Creative Commons Attribution International License (CC BY 4.0).

http://creativecommons.org/licenses/by/4.0/

\begin{abstract}
Our work aims to evaluate a complete outlook of virgin high density polyethylene (HDPE) and polypropylene (PP) polyblends. Virgin PP of 20, 30 and 50 weight $\%$ is compounded with virgin HDPE. The properties like tensile strength, flexural strength, Izod impact strength are examined. Scanning electron microscopy (SEM) and polarised light microscopy (PLM) are used to observe the surface and crystal morphology. X-ray diffraction (XRD), Fourier transform infrared spectroscopy (FTIR) tests verify the non compatibility of both polymers. Differential scanning calorimetry (DSC) and thermogravimetric analysis (TGA) techniques are used to study the thermal behaviour of composites. The results manifest co-occurring spherulites for polyblends; indicating the composite to be a physical blend of continuous and dispersed phases, but on the other hand PP improves the tensile and flexural properties of HDPE.
\end{abstract}

\section{Keywords}

High Density Poly Ethylene (HDPE), Polypropylene (PP), Polyblends, Mechanical, Thermal, Crystallization Properties

\section{Introduction}

Polymer composite is material of research in modern days. Thermoplastic polymers are of great interest due to their technical and commercial importance [1]. In general two or more polymers are melt blended to form a product as polyb- 
lends [2] [3] [4] [5]. The component percentages are the primary factor influencing their physical properties [6]. The manufacturing technique and operating conditions are second governing factor.

Among the thermoplastic polymers, PP possesses good mechanical strength. In addition it has high chemical resistance, low cost and easy to manufacture. PP has wide application in automobile spare parts and as well as container [7]. HDPE is known for its large strength to density ratio due to its little branching. HDPE unlike PP cannot withstand normally required autoclaving conditions [8]-[13].

Jia-Horny Lin et al. has reinforced HDPE to PP matrix and verified the noncompatibility of both polymers, but improves the impact strength of PP [14]. Souza et al found the effect of processing temperature and content of HDPE on interfacial tension of the PP/HDPE polyblend [15]. Past studies show the compatibility of PP/HDPE polyblends depends on factors like processing temperature, polymer structure and blending ratios [15] [16] [17]. Polymers with similar physical properties form polyblends with greater mechanical strength [18] [19] [20]. The mechanical properties of the PP/HDPE polyblend decreases with increase in dissimilarity of melt flow index (MFI) [21], so we have investigated a complete prospects of PP reinforced HDPE polyblends with similar MFI manufactured by the help of twin screw extruder and injection moulding machines. In addition to mechanical properties; thermal behaviour of the composites are characterised by using DSC, TGA tests. Crystal morphologies are captured using PLM, SEM and X-RD techniques. Compatibility of both the thermoplastics are re-examined by study of molecular structure using FTIR.

\section{Experimental}

\subsection{Collection of Polymers}

PP (M110 Grade, homopolymer) produced by the spheripol technology and HDPE (M5818 Grade, injection moulded type) produced by Mitsui Slurry CX technology are purchased from Haldia petrochemical limited, haldia, India. Different physical properties of the polymers are reported in Table 1.

\subsection{Preparation of Composites}

Polymers in the form of pellets are collected. The pellets are dried in a hot air oven at $60^{\circ} \mathrm{C}$ for $8 \mathrm{hrs}$ to remove moisture content followed by mixing of 20, 30, and $50 \mathrm{wt} \%$ of PP to HDPE. Then they are converted into polymer blend pellets using a twin screw extruder (ZV20, Specific Engineering and Auto Mates, Vadodara, India) at feeder speed of $51 \mathrm{rpm}$ and main rotor at $54 \mathrm{rpm}$. The screws are of $21 \mathrm{~mm}$ diameter and co-rotating type, containing three thermal barrels at $190^{\circ} \mathrm{C}, 200^{\circ} \mathrm{C}$ and $210^{\circ} \mathrm{C}$ respectively. The melt and die temperatures are $224^{\circ} \mathrm{C}$ and $200^{\circ} \mathrm{C}$.

The obtain pellets are dried at $60^{\circ} \mathrm{C}$ for $8 \mathrm{hrs}$ and moulded to test samples using an automatic injection moulding machine (Endura-90, Electonica plastic 
Table 1. Physical properties of polymers.

\begin{tabular}{ccc}
\hline Polymer type & Melt flow index (g/10 min $)$ & Density $(\mathrm{g} / \mathrm{cc})$ \\
\hline HDPE & $19\left(2.16 \mathrm{~kg}, 190^{\circ} \mathrm{C}\right)$ & 0.956 \\
PP & $11\left(2.16 \mathrm{~kg}, 230^{\circ} \mathrm{C}\right)$ & 0.900 \\
\hline
\end{tabular}

machines limited, Kolkata, India) with screw diameter of $35 \mathrm{~mm}$ at $177 \mathrm{rpm}$. The temperature of the nozzle is $200^{\circ} \mathrm{C}$ and that of the three barrels are $190^{\circ} \mathrm{C}$, $200^{\circ} \mathrm{C}$ and $210^{\circ} \mathrm{C}$ respectively. Snapshot of the prepared tensile and flexural test samples are shown in Figure 1.

\subsection{Mechanical Properties}

Both tensile and flexural strengths of HDPE/PP polyblends are tested using an universal testing machine (UTM3382, Instron, UK) as per ASTM D638-02a and ASTM D790 standards respectively. Tensile specimens are prepared according to ASTM D638-02a type-I; with gage length $50 \mathrm{~mm}$. Tests are conducted at cross head speed of $50 \mathrm{~mm} / \mathrm{min}$. Flexural sample of size $127 \mathrm{~mm} \times 12.7 \mathrm{~mm} \times 3.2 \mathrm{~mm}$ are tested at speed of $1.365 \mathrm{~mm} / \mathrm{min}$ with support span spacing of $51.2 \mathrm{~mm}$ ( $\operatorname{span}=16$ times of thickness) at an extension up to $5 \%$. The speed of the test and flexural strengths are calculated according to Equations (1) and (2) respectively.

$$
\begin{gathered}
\text { Speed }=\frac{Z L^{2}}{6 d} \\
\sigma_{F \text { max }}=\frac{3 P L}{2 b d^{2}}
\end{gathered}
$$

where, $Z$ is Rate of straining at $0.01 \mathrm{~mm} / \mathrm{mm} / \mathrm{min}, L$ is span length $(\mathrm{mm})$ and $d$ is sample thickness $(\mathrm{mm}), \sigma_{F \max }$ is flexural strength (MPa), $P$ is load $(\mathrm{N}), L$ is span length $(\mathrm{mm})$ and $b$ is sample width $(\mathrm{mm})$.

Impact tests are conducted using a Izod and Charpy impactometer (IT 504 Plastic impact, Tinius Olsen, USA ) with a V-notch cutter as per ASTM D256-A standard, possessing a pendulum energy of $13.70 \mathrm{~J}$. Impact test specimens are prepared by cutting the flexural samples to a size of $63.5 \mathrm{~mm} \times 12.7 \mathrm{~mm} \times 3.2$ $\mathrm{mm}$ with a $\mathrm{V}$-notch of $45^{\circ}$ and $0.25 \mathrm{~mm}$ depth.

\subsection{Microscopy Test}

Our investigation has used SEM (JEOL; JSM-6480 LV, Japan), Field emission SEM (Nova Nano SEM-450, USA) and PLM (Leica, DM750P, Germany). Morphology of samples is captured before and after fracture of impact test. Energy dispersive spectroscopy (EDS) analysis and carbon mapping test are conducted using FESEM at an operation voltage of $10 \mathrm{KV}$. Samples are gold coated before each test. PLM is used to observe the spherulite behaviour of the polyblends. A tiny sample is placed on a glass slide and melted at $200^{\circ} \mathrm{C}$ (using the hot stage) followed by sandwiching the sample by placing a micro glass slide over it to 


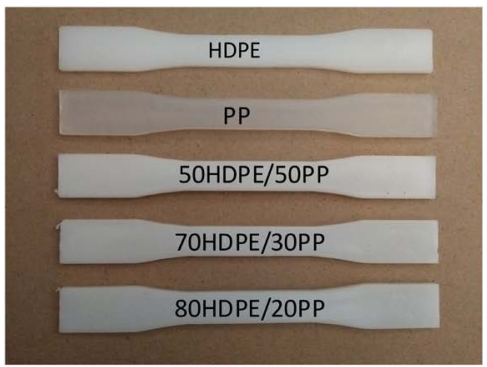

(a)

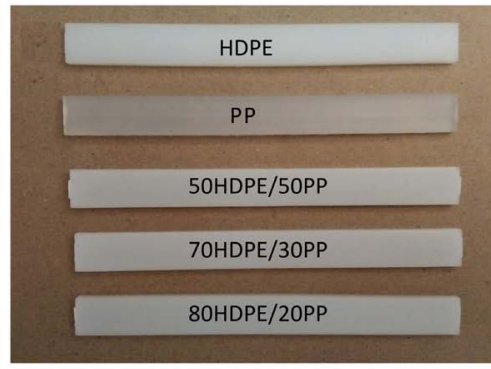

(b)

Figure 1. Snapshot of prepared, (a) tensile and (b) flexural test specimens.

form a thin film. The sample is cooled at $5^{\circ} \mathrm{C} / \mathrm{min}$ (using cold stage) and spherulite morphologies are captured at $130^{\circ} \mathrm{C}$ and $125^{\circ} \mathrm{C}$ at magnification $\times 10$.

\subsection{XRD and FTIR}

In order to analyse any new phase formations after blending the polymers and to understand the chemical structure of the polyblends; the XRD (Philips, PW1720, USA) and FTIR (Perkin-Emler Spectrum 100, USA) techniques are utilised. $\mathrm{X}$-ray scanning is done within a diffraction angle $(2 \theta)$ range of $10-90^{\circ}$ with $\mathrm{Cu} \mathrm{Ka}$ radiation at $40 \mathrm{KV}$ and $30 \mathrm{~mA}$. The rate of scanning is $10^{\circ} / \mathrm{min}$ and at $\lambda=0.154$ $\mathrm{nm}$. The IR Spectroscopy is observed between the waveband of 450 to $4000 \mathrm{~cm}^{-1}$.

\subsection{DSC and TGA Analyses}

The polyblends thermal behaviour is analysed using a DSC (Perkin-Elmer DSC 7, MA, USA) and TGA (Perkin-Elmer TGA, MA, USA) analysers. The DSC tests are performed under nitrogen flow rate of $50 \mathrm{ml} / \mathrm{min}$. Polymer samples of around $10 \mathrm{mg}$ are scanned at a heating rate of $10^{\circ} \mathrm{C} / \mathrm{min}$ from ambient temperature to $200^{\circ} \mathrm{C}$. The samples undergo three thermal cycles. Heating, cooling and reheating under the same condition to follow an identical thermal history for all polymer blends.

The degree of crystallinity $\left(X_{C}\right)$ of the polyblends is evaluated by Equation (3)

$$
X_{C}(\%)=\frac{\Delta H_{f}}{ø \Delta H_{f}^{0}} \times 100
$$

where, $\Delta H_{f}=$ Melting enthalpy of HDPE or PP in the blend, $\Delta H_{f}^{0}=$ Enthalpy corresponding to melting of $100 \%$ crystalline HDPE or PP and $\varnothing=$ weight fraction of HDPE or PP in the blend. In TGA test, polymer samples with masses of approximately $10 \mathrm{mg}$ are heated from atmospheric temperature to $600^{\circ} \mathrm{C}$, at heating rate of $10^{\circ} \mathrm{C} / \mathrm{min}$ and nitrogen flow rate of $50 \mathrm{ml} / \mathrm{min}$, to observe their degradation behaviour. Data corresponding to $\Delta H_{f}^{0}$ are referred from Roger L. Blaine [22].

\section{Results and Discussion}

\subsection{Tensile, Flexural and Impact Strengths}

Tensile strength results are shown in Figure 2(a). The maximum value $(\approx 35$ 
$\mathrm{MPa}$ ) of tensile strength is resulted from PP where as the HDPE matrix bears a tensile strength of $\approx 22 \mathrm{MPa}$. Reinforcement of PP to HDPE improves the tensile strength due to formation of brittle polyblends as observable in Figure 2(b). The magnitude of tensile modulus at break point is reported in Figure 2 (c). The polyblends of $50 \mathrm{HDPE} / 50 \mathrm{PP}$ shows the maximum $(\approx 146 \mathrm{MPa})$ value of tensile modulus.

The experimental outcomes for flexural tests are reported in Figure 3. Flexural strength improves (See Figure 3(a)) and a value of $\approx 23 \mathrm{MPa}$ is observed for all the composite blends. Figure 3 (b) reveals the PP added polyblends bear more extension properties when compare to HDPE. Data pertaining to the flexural modulus are reported in Figure 3(c); indicating the PP content increases the flexural modulus; as PP to be a separate phase in the polyblend and HDPE as continuous matrix.

The impact strength of polymers are expressed in three different ways and reported in Figure 4. The results corresponding to impact strength in Joule (J) is reported in Figure 4(a); indicating a maximum value for HDPE where as attributing a minimum value to 50/50 polyblend. Energy absorbed during impact per unit thickness of sample is manifested in Figure 4(b). The impact energy absorbed per unit cross sectional area, perpendicular to load; also shows a similar trend as visible in Figure 4(c). Reinforcement of PP particles to HDPE matrices contracts the stress concentration and the plastic deformation property is lost; there by weakening the impact property.

\subsection{Phase Analysis}

The chemical and crystal structure of HDPE/PP polyblends are analysed by XRD and FTIR. Figure 5 and Figure 6 reports the XRD and FTIR results. For PP all the peaks lies between $2 \theta$ of 15 to $30^{\circ}$, which are a form of PP. The peaks are corresponding to crystalline lattices [23]. Two diffraction peaks for HDPE are observed between 20 to $30^{\circ}$ diffraction angles, comprising of orthorhombic crystals [24] [25]. Reinforcing PP to HDPE does not produce any new peaks, only shortening of peaks for HDPE/PP polyblends are seen. So combination of PP with HDPE is only a physical mixing with no alternation of chemical structure. Table 2 shows the frequency ranges of different functional groups of PP and HDPE polymers, with assigned vibration type. The FTIR spectra reveals, the peaks of HDPE/PP composites confirms to those of virgin HDPE and PP matrices.

\subsection{Thermal Behaviour}

From the DSC study the melting temperature $\left(T_{m}\right)$ of PP and HDPE are 168.6 and $134.6^{\circ} \mathrm{C}$ respectively. Table 3 reports the detailed results of melting temperature and melt enthalpy ( $\Delta H_{f}$ ) of all the polymer type. The HDPE/PP polyblend bears two melt points as shown in Figure 7(a); indicating the polyblend to be a co-occurrence of both HDPE and PP. The results authenticate the polymer 


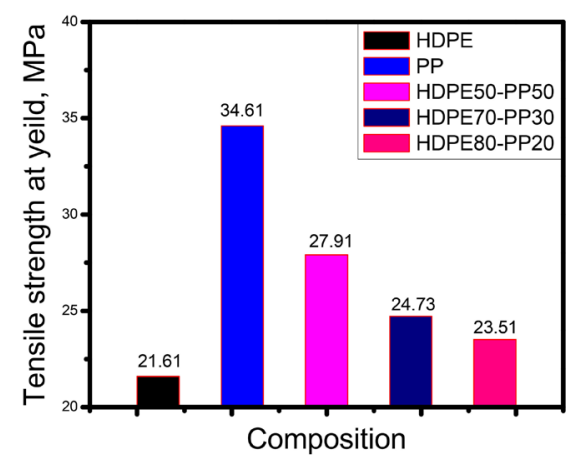

(a)

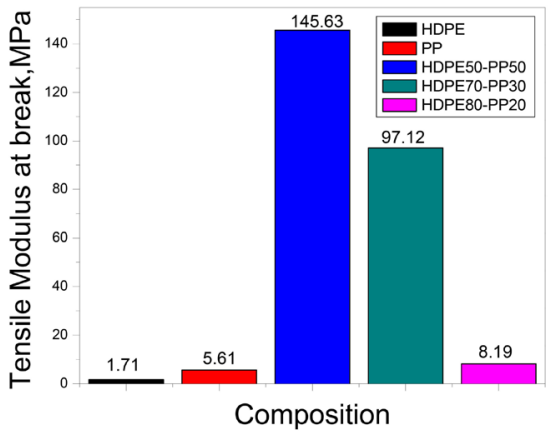

(c)

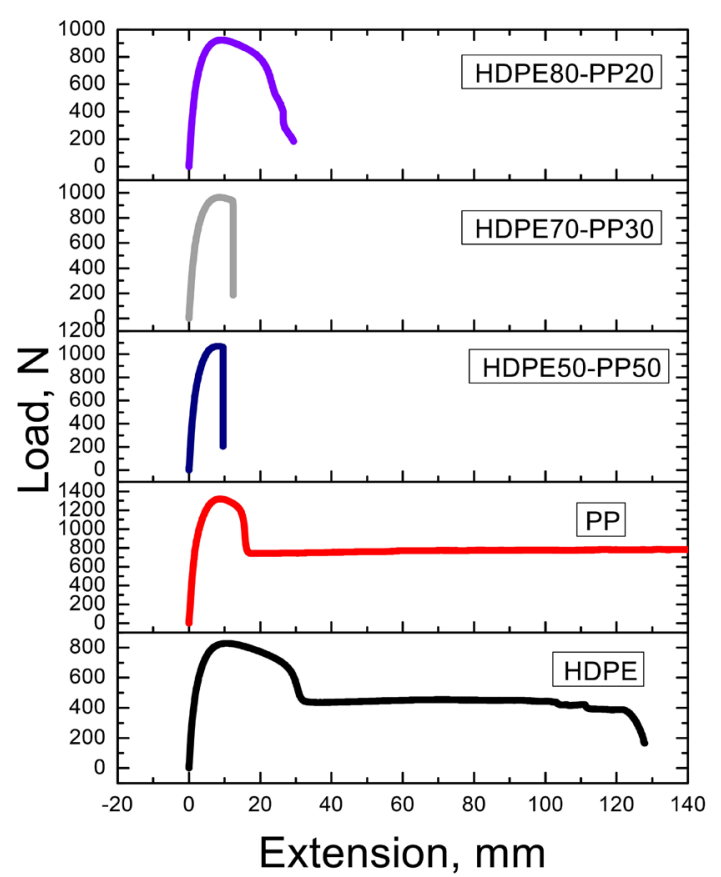

(b)

Figure 2. Tensile properties of the polymer composites, (a) tensile strength at yield; (b) load against extension; (c) tensile modulus at break.

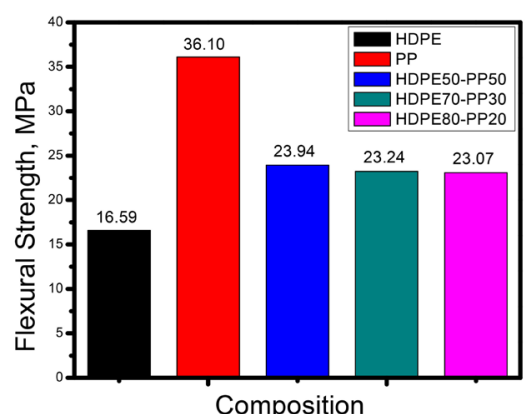

(a)

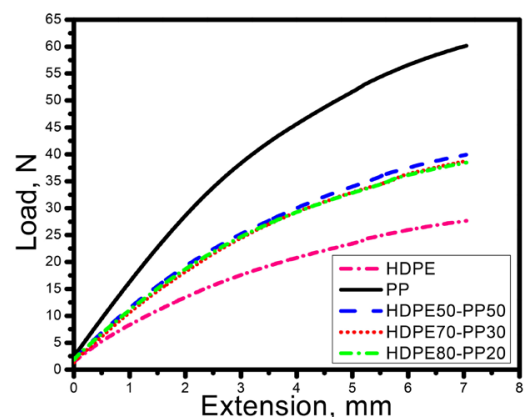

(b)

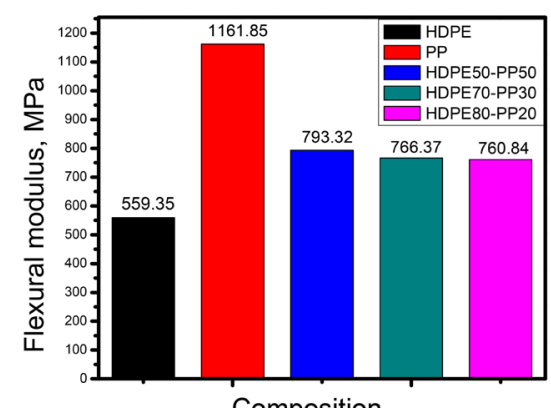

Composition

(c)

Figure 3. Flexural properties of the polyblends, (a) flexural strength; (b) load vs extension; (c) flexural modulus.

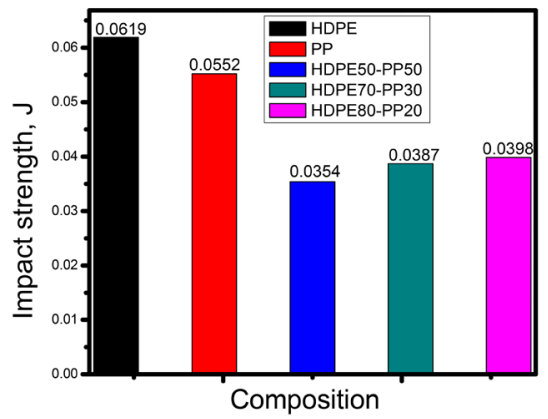

(a)

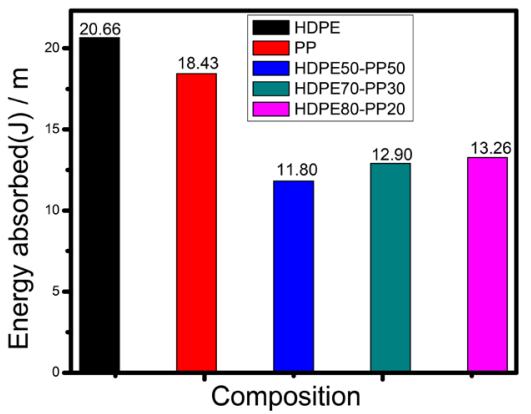

(b)

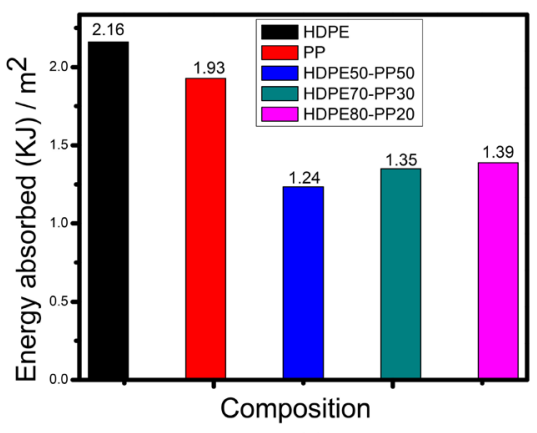

(c)

Figure 4. Impact strengths of the polyblends, (a) energy absorbed; (b) energy absorbed/m of sample thickness; (c) energy absorbed/unit cross sectional area. 


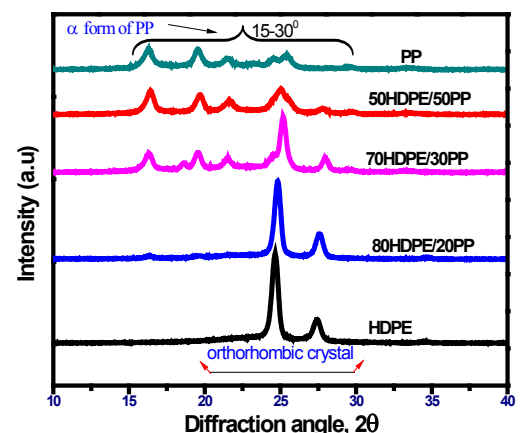

Figure 5. X-Ray diffractogram of polymer composite blends.

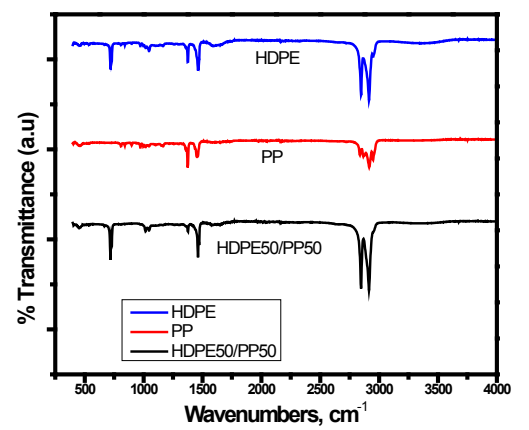

Figure 6. FT-IR spectroscopy of polymer composite blends.

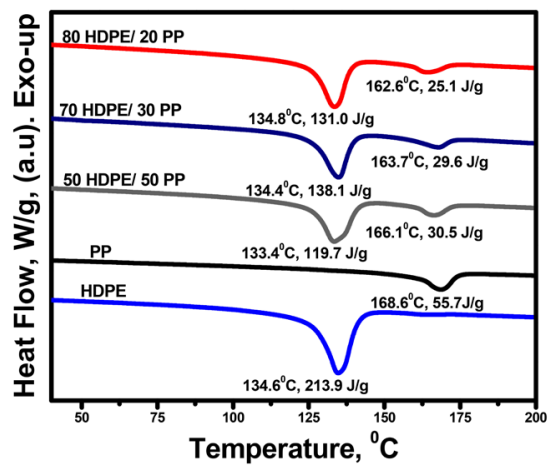

(a)

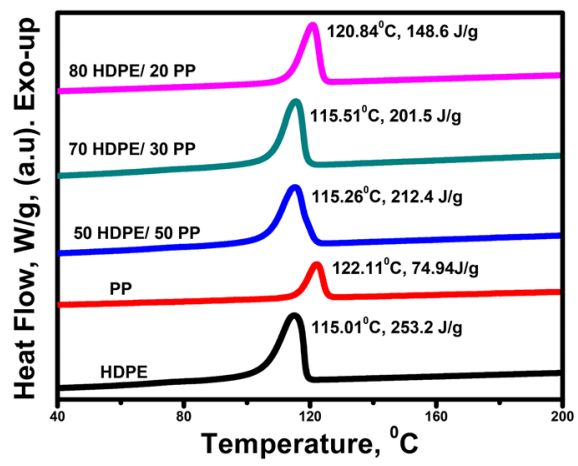

(b)

Figure 7. DSC sketches of the obtained polyblends; (a) heating; (b) cooling cycles. 
Table 2. IR spectra analysis reports.

\begin{tabular}{cccc}
\hline Group & Wave number $\left(\mathrm{cm}^{-1}\right)$ & Vibration type & Assigned to \\
\hline$-\mathrm{C}-\mathrm{H}$ & $2985-2810$ & Stretching & PP \\
$-\mathrm{CH}_{2}$ & $2950-2850$ & Stretching & HDPE \\
$-\mathrm{CH}_{2}$ & $1475-1440$ & Bending & PP \\
$-\mathrm{CH}_{3}$ & $1380-1370$ & Bending & PP \\
$-\mathrm{CH}_{2}$ & $1470-1460$ & Bending & HDPE \\
$-\mathrm{CH}_{2}$ & $730-700$ & Rocking & HDPE \\
\hline
\end{tabular}

Table 3. DSC data of HDPE/PP polyblends.

\begin{tabular}{cccccc}
\hline Polymer Type & $\Delta H_{f}, \mathrm{~J} / \mathrm{g}$ & $\mathrm{T}_{\mathrm{m}},{ }^{\circ} \mathrm{C}$ & $\mathrm{T}_{c},{ }^{\circ} \mathrm{C}$ & $X_{c}, \%$ & $\Delta H_{c}, \mathrm{~J} / \mathrm{g}$ \\
\hline HDPE & 213.9 & 134.6 & 115.0 & 73.0 & 253.2 \\
PP & 55.7 & 168.6 & 122.1 & 26.9 & 74.94 \\
50HDPE/50PP & $119.7^{\mathrm{a}} / 30.5^{\mathrm{b}}$ & $134.4^{\mathrm{a}} / 166.1^{\mathrm{b}}$ & 115.2 & $81.70^{\mathrm{a}} / 29.46^{\mathrm{b}}$ & 212.4 \\
$70 \mathrm{HDPE} / 30 \mathrm{PP}$ & $138.1^{\mathrm{a}} / 29.6^{\mathrm{b}}$ & $134.4^{\mathrm{a}} / 163.7^{\mathrm{b}}$ & 115.5 & $67.33^{\mathrm{a}} / 47.66^{\mathrm{b}}$ & 201.5 \\
80HDPE/20PP & $131.0^{\mathrm{a}} / 25.1^{\mathrm{b}}$ & $134.8^{\mathrm{a}} / 162.6^{\mathrm{b}}$ & 120.8 & $55.88^{\mathrm{a}} / 60.62^{\mathrm{b}}$ & 148.6 \\
\hline
\end{tabular}

The superscript ${ }^{\mathrm{ab}}$ corresponds to cite HDPE and PP respectively.

composite to be a physical mixture of both the polymers. The existence of PP in HDPE does not alter the melt peak temperature significantly.

Figure $7(\mathrm{~b})$ shows the temperature $\left(\mathrm{T}_{c}\right)$ and enthalpy $\Delta H_{c}$ of crystallization for all the polymers resulted from the DSC cooling cycle. The $\mathrm{T}_{c}$ 's for PP and HDPE are $122.11^{\circ} \mathrm{C}$ and $115.01^{\circ} \mathrm{C}$ respectively. Result shows PP crystallizes faster than HDPE. But the order of crystallinity of the composite blend is quite similar to HDPE. Augmentation of PP particles to HDPE retards the nucleation of the heterogeneous polymer blend and so the crystallization peaks of the polyblends are undistinguishable.

The weight loss of a polymer with respect to time or temperature is usually predicted by using TGA technique. The thermal degradation is an irreversible process. Our work focused to predict the degradation temperature $\left(T_{D}\right)$. It is defined in our project as; the temperature at which the weight loss of the polymers just starts to fall immediately. Figure 8 shows TG/DTG thermogram sketches of our prepared polymers. The results obtained via TG analysis on polymers are revealed in Table 4. All the samples undergo a single degradation step. The inflection point $\left(\mathrm{I}_{\mathrm{p}}\right.$, at which the rate of weight change with temperature is maximum) and residual weight $\%$ are also reported in Table 4. It is evident from the results that, the thermal behaviour of the binary polyblends differ marginally; may be due to similar density and MFI. 


\subsection{Surface Behavior}

The surface morphology of polymers before fracture is reported in Figure 9. A

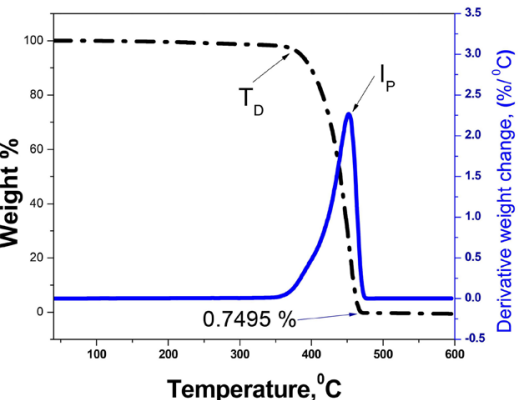

(a)

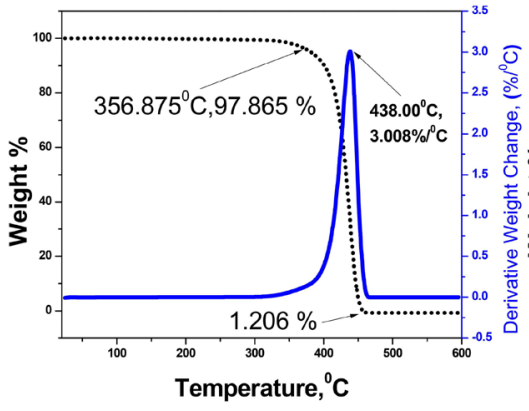

(b)

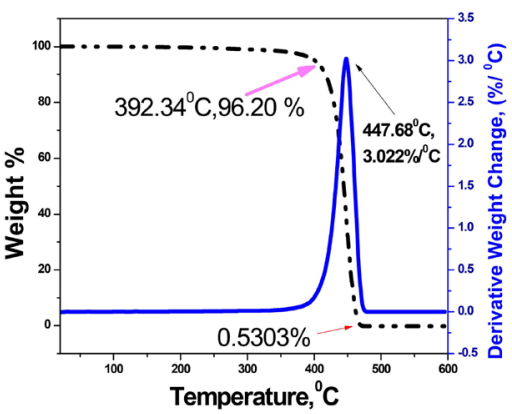

(c)

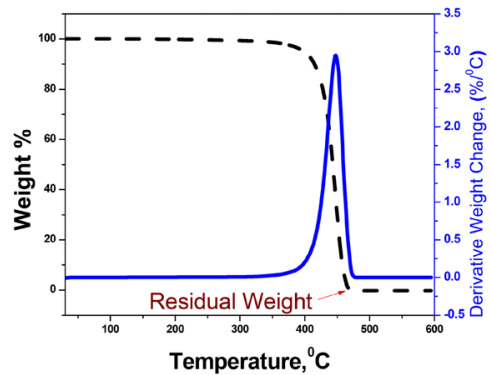

(d)

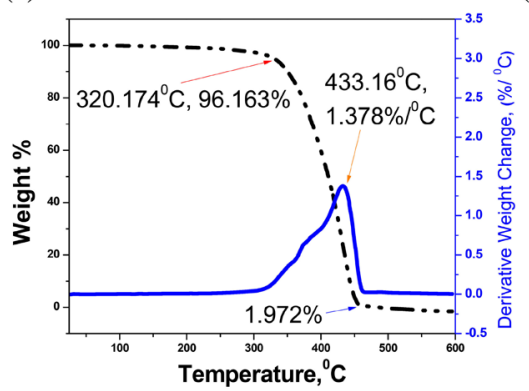

(e)

Figure 8. TG/DTG thermograms of (a) virgin HDPE; (b) virgin PP, and HDPE/PP Polyblends which contain; (c) 50 wt\%; (d) $30 \mathrm{wt} \%$ and (e) $20 \mathrm{wt} \%$ of PP.

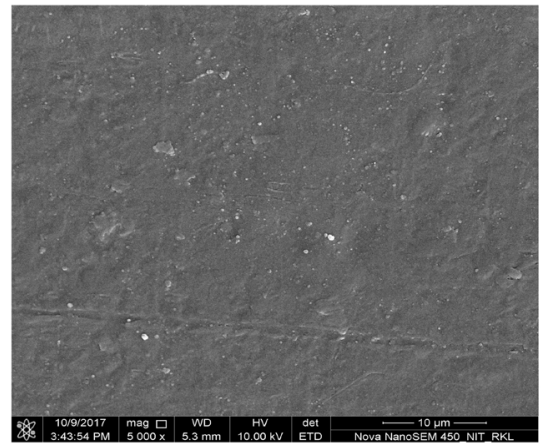

(a)

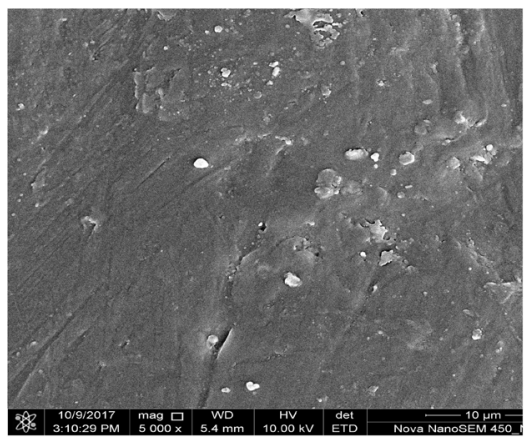

(d)

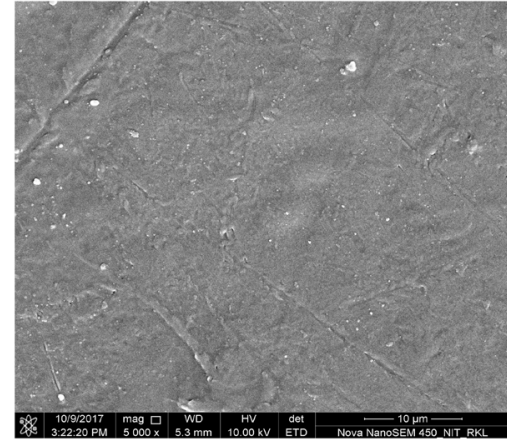

(b)

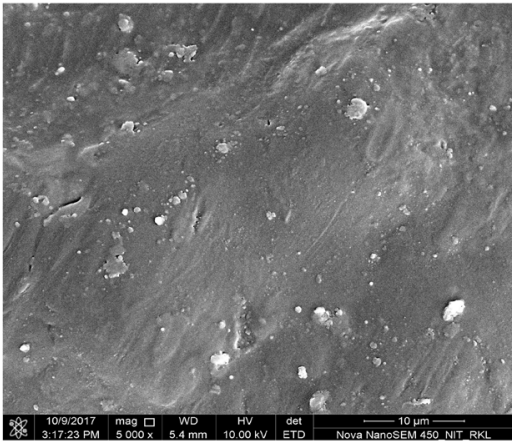

(c)

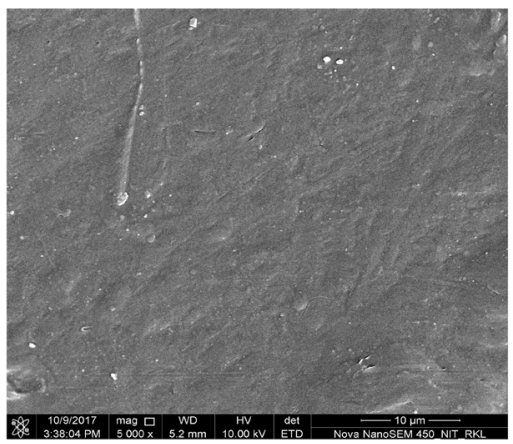

(e)

Figure 9. Surface morphology of un-fractured Polyblends; (a) virgin HDPE; (b) virgin PP, and HDPE/PP polyblends which contain; (c) $50 \mathrm{wt} \%$; (d) $30 \mathrm{wt} \%$ and (e) $20 \mathrm{wt} \%$ of PP. 
Table 4. TG/DTG results of prepared polymers.

\begin{tabular}{cccccc}
\hline \multirow{2}{*}{ Sample } & $\mathrm{T}_{\mathrm{D}},{ }^{\circ} \mathrm{C}$ & Weight $\%$ at $\mathrm{T}_{\mathrm{D}}$ & Residual weight $\%$ & \multicolumn{2}{c}{ Inflection Point } \\
\cline { 5 - 6 } HDPE & 368.56 & 97.45 & 0.7495 & 452.5 & 2.264 \\
$\mathrm{PP}$ & 356.87 & 97.86 & 1.206 & 438.0 & 3.008 \\
\hline 50HDPE/50PP & 392.34 & 96.20 & 0.5303 & 447.68 & 3.002 \\
$70 \mathrm{HDPE} / 30 \mathrm{PP}$ & 388.54 & 96.45 & 0.6602 & 447.65 & 2.94 \\
\hline 80HDPE/20PP & 320.174 & 96.16 & 1.972 & 433.16 & 1.378 \\
\hline
\end{tabular}

similar morphology of all the polymer blends is observed. Prepared sample's surfaces are smooth and difficult to differentiate. The continuous and dispersed phases for un-fractured polyblend samples are difficult to identify. To evaluate the changes in the properties; carbon elemental mapping and EDS tests are conducted and disclosed in Figure 10. Surface behaviour of fractured specimens after impact test is shown in Figure 11. Figure 11(b) shows the fractured surface for virgin PP is flat owing to brittle fracture. Fractured virgin HDPE specimen results a wrinkled and aggregative exterior. The ruptured surface of the polyblends is also irregular, owing to their toughness. The reinforcement of PP to HDPE smoothens the surface as visible in Figures 2(c)-(e). The impact energy absorbed falls with augmentation of PP particles (see Figure 4), resulting the cracks to prevent bloating due to exerted strain.

Crystal structures of the polyblends during solidification from molten stage are reported in Figure 12. Spherulites are large and spherical for PP conforming to the results reported by jia-Horng Lin etal [14], and so called ring spherulites for HDPE. PP forms an overlapped layer in the polyblend and hence an incomplete spherulitic growth is resulting for the polymer composites. Spherulites stalk over each and cannot reach to complete form.

\section{Conclusion}

Our project promisingly combines PP with HDPE. The dispersion of PP in HDPE improves tensile and flexural strengths. The results show that a $50 \mathrm{wt} \%$ PP increases the tensile strength of the composite by $29 \%$, and is maximum among the polymer blends. The magnitude of the flexural strength for all the polyblends are close to $23 \mathrm{MPa}$ and improved by $44 \%$. The XRD, FTIR and DSC tests prove the polyblend to be a combination of two dispersed matrices. No changes in chemical structure are observed, confirming the composite to be a physical blending. PLM tests authenticate; reinforcement of PP particles to HDPE retards the crystal growth and spherulites lap over. TGA tests disclose the degradation characteristics; showing a maximum degradation temperature and weight loss for polymer blends is for composite with $50 \mathrm{wt} \% \mathrm{PP}$. Because of the 


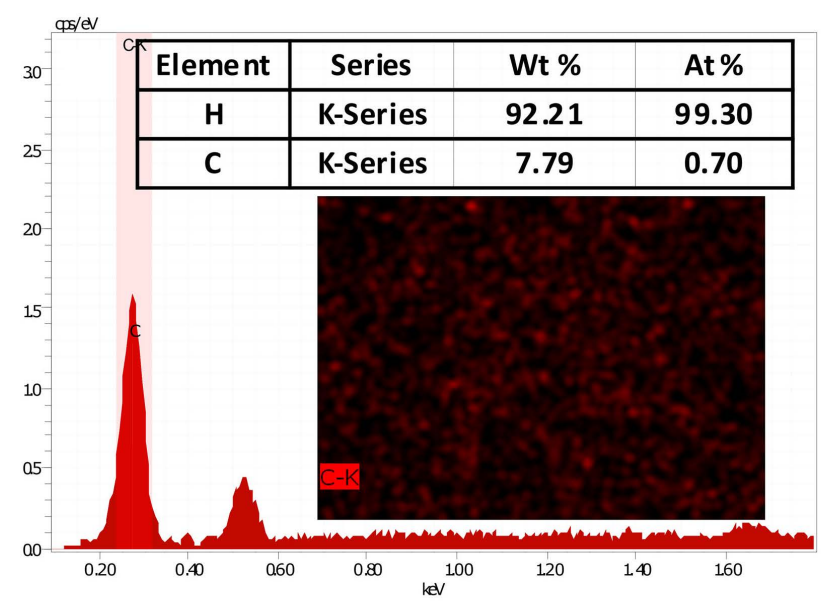

(a)

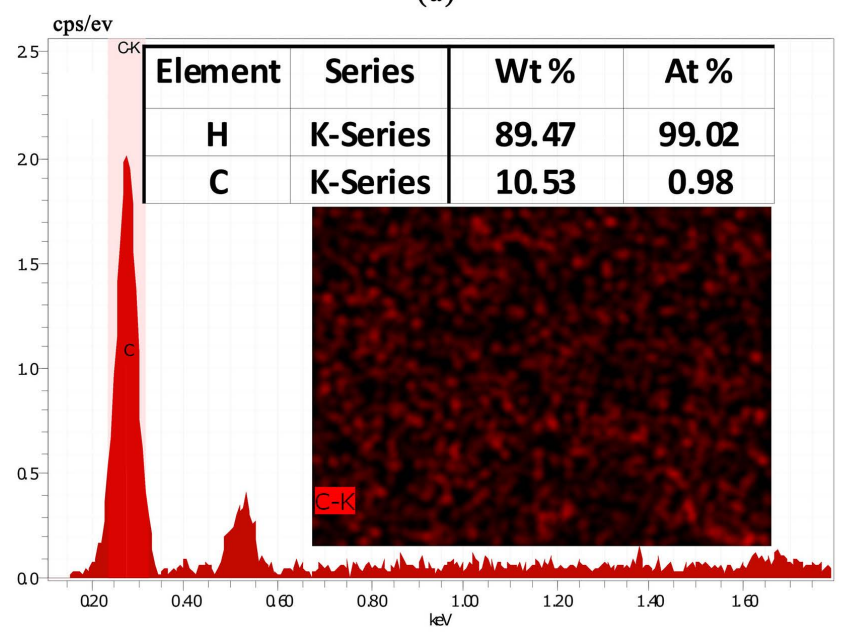

(c)

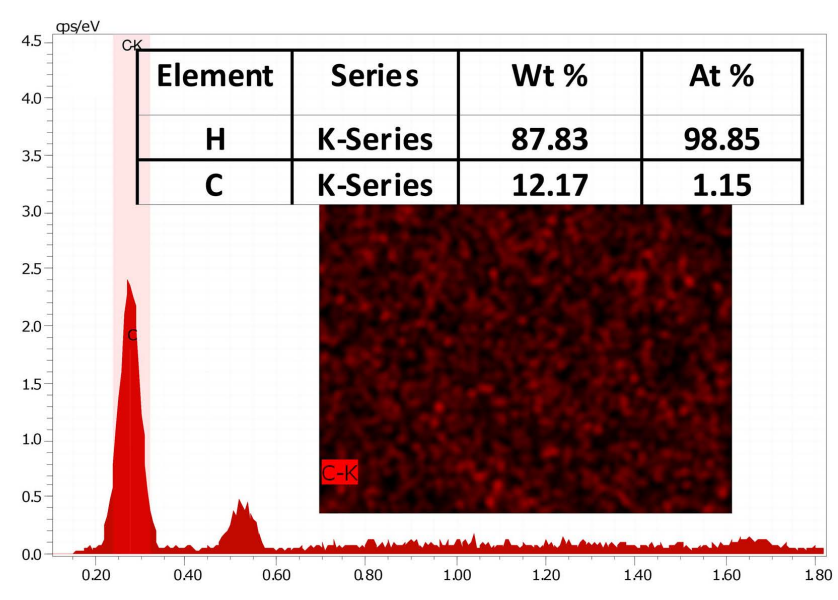

(b)

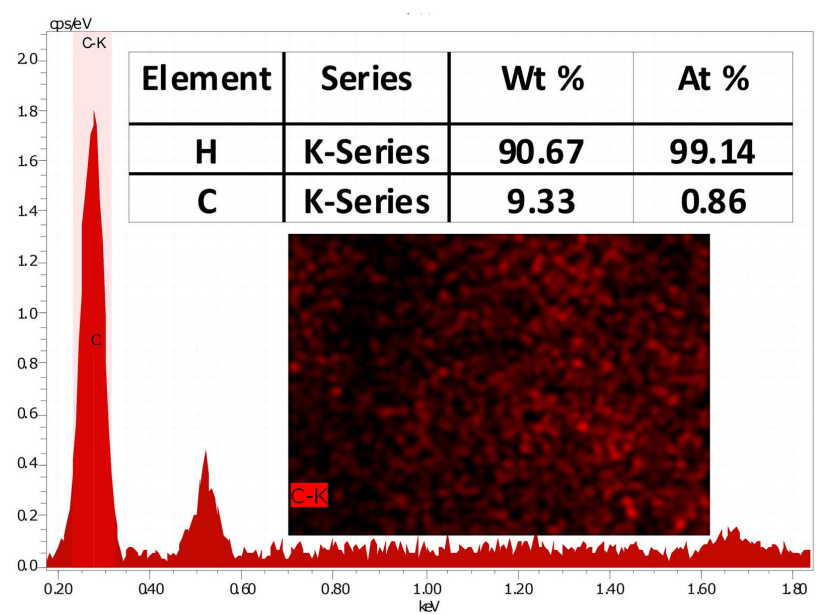

(d)

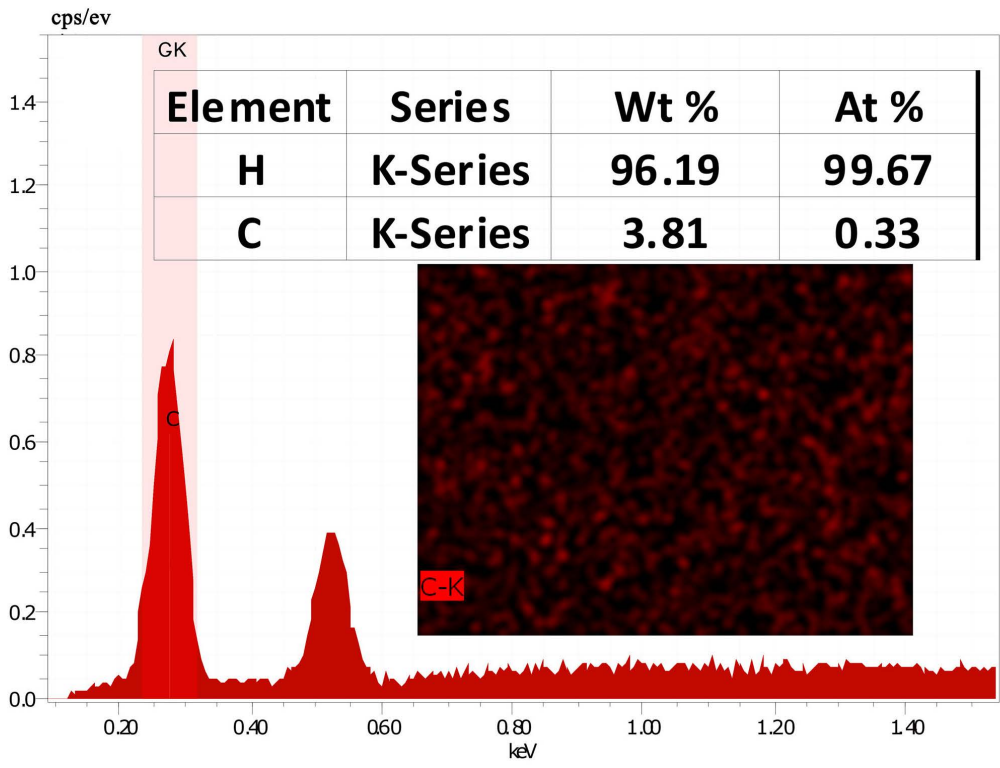

(e)

Figure 10. EDS and carbon element mapping of Polyblends; (a) virgin HDPE; (b) virgin PP, and HDPE/PP Polyblends which contain; (c) $50 \mathrm{wt} \%$; (d) $30 \mathrm{wt} \%$ and (e) $20 \mathrm{wt} \%$ of PP. 


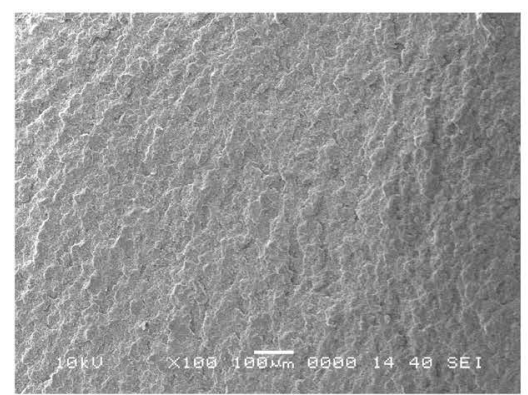

(a)

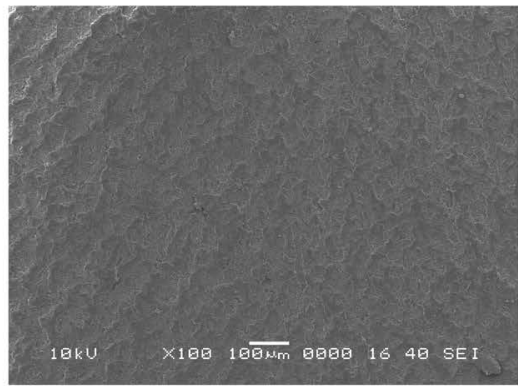

(d)

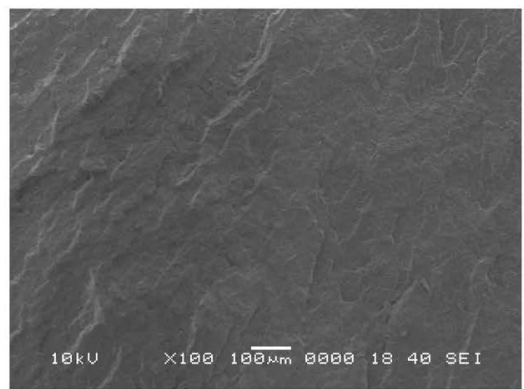

(b)

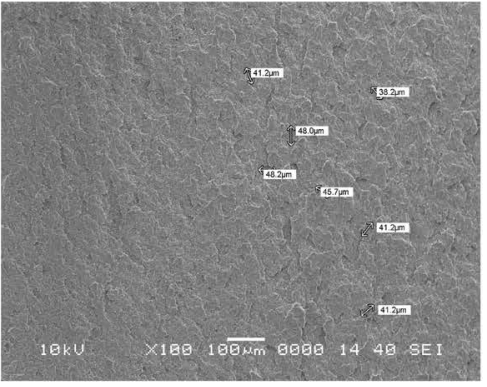

(e)

Figure 11. SEM images of the fractured specimens after impact tests; (a) virgin HDPE; (b) virgin PP and polyblends which contain (c) $50 \mathrm{wt} \%$; (d) $30 \mathrm{wt} \%$; (e) $20 \mathrm{wt} \%$ of PP.

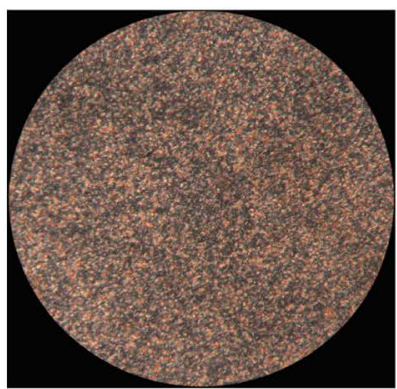

(a)

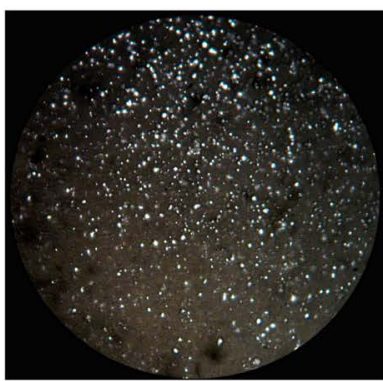

(e)

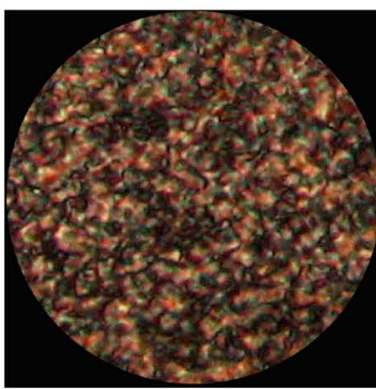

(b)

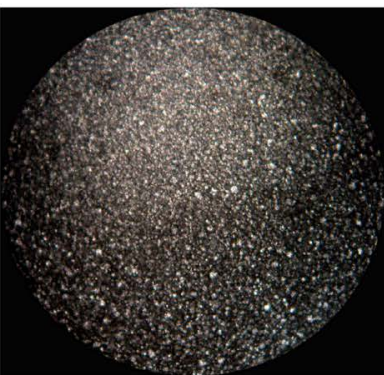

(f)

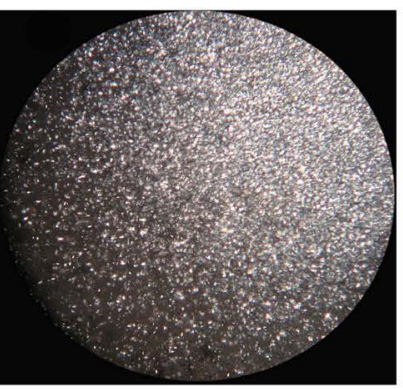

(c)

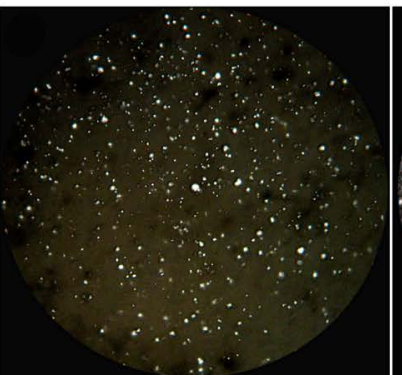

(g)

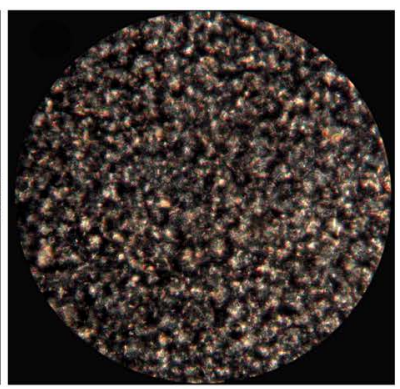

(d)

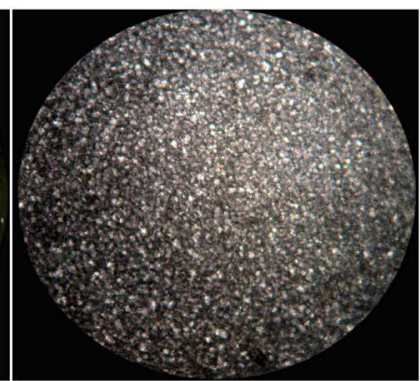

(h)

Figure 12. Spherulite structures of prepared polymers (a) HDPE at $130^{\circ} \mathrm{C}$; (b) $\mathrm{HDPE}$ at $125^{\circ} \mathrm{C}$; (c) $\mathrm{PP}$ at $130^{\circ} \mathrm{C}$; (d) $\mathrm{PP}$ at $125^{\circ} \mathrm{C}$; (e) $50 \mathrm{HDPE} / 50 \mathrm{PP}$ at $130^{\circ} \mathrm{C}$; (f) $50 \mathrm{HDPE} / 50 \mathrm{PP}$ at $125^{\circ} \mathrm{C}$; (g) $80 \mathrm{HDPE} / 20 \mathrm{PP}$ at $130^{\circ} \mathrm{C}$; (h) $80 \mathrm{HDPE} / 20 \mathrm{PP}$ at $125^{\circ} \mathrm{C}$.

conventional methods are adopted for preparing the HDPE/PP blends with low manufacturing cost, the composite blends may find suitable application areas.

\section{References}

[1] Erbetta, C.D.C., Azevedo, R.C.S., Andrade, K.S., e Silva, M.E.S.R. and Roberto, 
F.S.F. (2017) Characterization and Lifetime Estimation of High Density Polyethylene Containing a Prodegradant Agent. Materials Sciences and Applications, 8, 979-991. https://doi.org/10.4236/msa.2017.813072

[2] Bertin, S. and Robin, J. (2002) Study and Characterization of Virgin and Recycled LDPE/PP Blends. European Polymer Journal, 38, 2255-2264. https://doi.org/10.1016/S0014-3057(02)00111-8

[3] Laoutid, F., Estrada, E., Michell, R.M., Bonnaud, L., Müller, A.J. and Dubois, P. (2013) The Influence of Nanosilica on the Nucleation, Crystallization and Tensile Properties of PP-PC and PP-PA Blends. Polymer, 54, 3982-3993. https://doi.org/10.1016/j.polymer.2013.05.031

[4] Xie, B.H., Huang, X. and Zhang G.J. (2013) High Thermal Conductive Polyvinyl Alcohol Composites with Hexagonal Boron Nitride Microplatelets as Fillers. Composites Science and Technology, 85, 98-103. https://doi.org/10.1016/j.compscitech.2013.06.010

[5] Ma, W., Zhang, J. and Wang, X. (2008) Crystallizaion and Surface Morphology of Poly(vinylidene fluoride)/Poly(methylmethacrylate) Films by Solution Casting on Different Substrates. Applied Surface Science, 254, 2947-2954.

https://doi.org/10.1016/j.apsusc.2007.10.037

[6] Albano, C., González, J., Ichazo, M., Rosales, C., Urbina de Navarro, C. and Parra, C. (2000) Mechanical and Morphological Behavior of Polyolefin Blends in the Presence of CaCO3. Composite Structures, 48, 49-58. https://doi.org/10.1016/S0263-8223(99)00072-0

[7] Hsieh, C.T., Pan, Y.J. and Lin, J.H. (2017) Polypropylene/High-Density Polyethylene/Carbon Fiber Composites: Manufacturing Techniques, Mechanical Properties, and Electromagnetic Interference Shielding Effectiveness. Fibers and Polymers, 18, 155-161. https://doi.org/10.1007/s12221-017-6371-0

[8] Wilkinson, A.N., Laugel, L., Clemens, M.L., Harding, V.M. and Marin, M. (1999) Phase Structure in Polypropylene/PA6/SEBS Blends. Polymer, 40, 4971-4975. https://doi.org/10.1016/S0032-3861(98)00843-X

[9] Tseng, F.P., Lin, J.J. and Tseng, C.R. (2001) Poly (oxypropylene)-Amide Grafted Polypropylene as Novel Compatibilizer for PP and PA6 Blends. Polymer, 42, 713-725. https://doi.org/10.1016/S0032-3861(00)00400-6

[10] Shi, H., Shi, D., Wang, X., Yin, L., Yin, J. and Mai, Y.W. (2010) A Facile Route for Preparing Stable Co-Continuous Morphology of LLDPE/PA6 Blends with Low PA6 Content. Polymer, 51, 4958-4968. https://doi.org/10.1016/j.polymer.2010.08.023

[11] Maciel, A., Salas, V. and Manero, O. (2005) PP/EVA Blends: Mechanical Properties and Morphology. Effect of Compatibilizers on the Impact Behavior. Advances in Polymer Technology, 24, 241-252. https://doi.org/10.1002/adv.20050

[12] Martins, C.G., Larocca, N.M., Paul, D.R. and Pessan, L.A. (2009) Nanocomposites Formed from Polypropylene/EVA Blends. Polymer, 50, 1743-1754. https://doi.org/10.1016/j.polymer.2009.01.059

[13] Valera-Zaragoza, M., Rivas-Vazquez, L.P., Ramirez-Vargas, E., Sánchez-Valdes, S., Ramos-deValle, L.F. and Medellín-Rodríguez, F.J. (2013) Influence of Morphology on the Dynamic Mechanical Characteristics of PP-EP/EVA/Organoclay Nanocomposites. Composites Part B: Engineering, 55, 506-512. https://doi.org/10.1016/j.compositesb.2013.07.009

[14] Lin, J.H., Pan, Y.J., Liu, C.F., Huang, C.L., Hsieh, C.T., Chen, C.K., Lin, Z.Y. and Lou, C.W. (2015) Preparation and Compatibility Evaluation of Polypropylene/High Density Polyethylene Polyblends. Materials, 8, 8850-8859. 
https://doi.org/10.3390/ma8125496

[15] Souza, A.M.C. and Demarquette, N.R. (2002) Influence of Composition on the Linear Viscoelastic Behavior and Morphology of PP/HDPE Blends. Polymer, 43, 1313-1321. https://doi.org/10.1016/S0032-3861(01)00718-2

[16] Li, J., Shanks, R.A. and Long, Y. (2000) Mechanical Properties and Morphology of Polyethylene-Polypropylene Blends with Controlled Thermal History. Journal of Applied Polymer Science, 76, 1151-1164.

https://doi.org/10.1002/(SICI)1097-4628(20000516)76:7<1151::AID-APP19>3.0.CO $\underline{; 2-\mathrm{H}}$

[17] Jose, S., Aprem, A.S., Francis, B., Chandy, M.C., Werner, P., Alstaedt, V. and Thomas, S. (2004) Phase Morphology, Crystallisation Behaviour and Mechanical Properties of Isotactic Polypropylene/High Density Polyethylene Blends. European Polymer Journal, 40, 2105-2115. https://doi.org/10.1016/j.eurpolymj.2004.02.026

[18] Macosko, C.W., Jeon, H.K. and Hoye, T.R. (2005) Reactions at Polymer-Polymer Interfaces for Blend Compatibilization. Progress in Polymer Science, 30, 939-947. https://doi.org/10.1016/j.progpolymsci.2005.06.003

[19] Saroop, M. and Mathur, G.N. (1997) Studies on the Dynamically Vulcanized Polypropylene (PP)/Butadiene Styrene Block Copolymer (SBS) Blends: Mechanical Properties. Journal of Applied Polymer Science, 65, 2691-2701. https://doi.org/10.1002/(SICI)1097-4628(19970926)65:13<2691::AID-APP10>3.0.C $\underline{\mathrm{O} ; 2-0}$

[20] Van Puyvelde, P., Velankar, S. and Moldenaers, P. (2001) Rheology and Morphology of Compatibilized Polymer Blends. Current Opinion in Colloid and Interface Science, 6, 457-463. https://doi.org/10.1016/S1359-0294(01)00113-3

[21] Camacho, W. and Karlsson, S. (2001) NIR, DSC and FTIR as Quantitative Methods for Compositional Analysis of Blends of Polymers Obtained from Recycled Mixed Plastic Waste. Polymer Engineering and Science, 41, 1626-1635. https://doi.org/10.1002/pen.10860

[22] Blaine, R.L. Thermal Applications Note, Polymer Heats of Fusion.

[23] Nishino, T., Matsumoto, T. and Nakamae, K. (2000) Surface Structure of Isotactic Polypropylene by X-Ray Diffraction. Polymer Engineering and Science, 40, 336-343. https://doi.org/10.1002/pen.11167

[24] Inci, B. and Wagener, K.B. (2011) Decreasing the Alkyl Branch Frequency in Precision Polyethylene: Pushing the Limits toward Longer Run Lengths. Journal of the American Chemical Society, 133, 11872-11875. https://doi.org/10.1021/ja2040046

[25] Liao, C.Z. and Tjong S.C. (2012) Mechanical and Thermal Performance of High-Density Polyethylene/Alumina Nanocomposites. Journal of Macromolecular Science, Part B, 52, 812-825. https://doi.org/10.1080/00222348.2012.733297 